\title{
Graphene Sheets with Modified Surface by Sodium Lauryl Sulfate Surfactant for Biomedical Applications
}

\section{Zhypargul Abdullaeva1* ${ }^{*}$, Zhazgul Kelgenbaeva1, Tsushida Masayuki', Megumi Hirano², Shoji Nagaoka ${ }^{3}$, Tomohiro Shirosaki ${ }^{3}$}

${ }^{1}$ Department of Materials Science and Engineering, Kumamoto University, Kumamoto, Japan

${ }^{2}$ Applied Chemistry and Biochemistry Department, Kumamoto University, Kumamoto, Japan

${ }^{3}$ Materials Development Department, Kumamoto Industrial Research Institute, Kumamoto, Japan

Email: *jypara@kumamoto-u.ac.jp

How to cite this paper: Abdullaeva, Z., Kelgenbaeva, Z., Masayuki, T., Hirano, M., Nagaoka, S. and Shirosaki, T. (2016) Graphene Sheets with Modified Surface by Sodium Lauryl Sulfate Surfactant for Biomedical Applications. Graphene, 5, 155-165. http://dx.doi.org/10.4236/graphene.2016.54013

Received: August 19, 2016

Accepted: September 26, 2016

Published: September 29, 2016

Copyright $\odot 2016$ by authors and Scientific Research Publishing Inc. This work is licensed under the Creative Commons Attribution International License (CC BY 4.0).

http://creativecommons.org/licenses/by/4.0/ (c) (i) Open Access

\begin{abstract}
This work describes synthesis of graphene sheets with modified surface by sodium lauryl sulfate (SLS) surfactant using one-pot solvothermal reaction method. Effect of sodium lauryl sulfate surfactant amount on surface modification level of graphene sheets was investigated. Ether (-S-OR- at $\left.762 \mathrm{~cm}^{-1}-863 \mathrm{~cm}^{-1}\right)$, thiocarbonyl $(=\mathrm{C}=\mathrm{S}$ at $1050 \mathrm{~cm}^{-1}-1176 \mathrm{~cm}^{-1}$ ) and sulfoxide (S-O, $V_{s}$ and $V_{a s}$ at $1030 \mathrm{~cm}^{-1}-1450 \mathrm{~cm}^{-1}$ ) functional groups released from sodium lauryl sulfate (SLS) surfactant during solvothermal reaction and attached on the surface of graphene sheets were detected by (attenuated total reflectance-fast Fourier infrared) ATR-FTIR spectroscopy. (Atomic force microscope) AFM observations revealed apparent surface of graphene sheets modified by surfactant molecules with an average multiple profile of graphene nanosheets $\approx 4.8 \mathrm{~nm}$ high. This synthesis way of surface modified graphene sheets can be considered as easy, one-step and cheap method for manufacturing of novel biosurface with graphene, as reinforcement for biopolymer coatings such as ultra-high molecular weight polypropylene (UHMWPE), metallic biomaterials ( $\mathrm{Ti}$ and $\mathrm{Ti}$ alloys) and bioceramics as hydroxyapatite (HA).
\end{abstract}

\section{Keywords}

Graphene, Synthesis, Surface Modification, Surfactant, Attenuated Total Reflection

\section{Introduction}

Graphene is one of allotropic modifications of carbon element with atomic number 6, located in the Periodic table of chemical elements, which was notable Nobel Prize in 
Physics by A. Geim and K. Novoselov [1]-[3]. Graphene's structure is basically composed of monolayer carbon atoms hexagonal lattice, in which individual carbon atoms are connected by $\mathrm{sp}^{2}$ bonds, similar to those of nanotubes, fullerenes and carbon onions [4] [5]. Graphene is defining as two-dimensional (2D) material [6] [7], due to its width and length characteristics. Recent progress has shown that the graphene-based materials can have a deep impact on electronic and optoelectronic devices, chemical sensors, nanocomposites and energy storage [8]. Fabrication of graphene was achieved by several methods: chemical reduction [9], plasma let [10], chemical vapor deposition [11], and so on [12].

Chemical modification of graphene dispersion by surfactants in the content of manufacturing and commercialization was reported [13].

Sodium lauryl sulphate (SLS)-modified activated carbon from risk husk for waste lead $\mathrm{Pb})$ removal was synthesized by using of series of treatments, such as: carbonization, activation with $\mathrm{H}_{3} \mathrm{PO}_{4}$ and surface modification using sodium lauryl sulfate (SLS) [14].

This work was aimed to synthesize graphene sheets with modified surface by sodium lauryl sulfate (SLS) surfactant, using the simple and one-pot solvothermal reaction method. Solvothermal method is based on a chemical reaction between initial substances, mainly, the solvent and dissolved substances in it. Solvothermal reaction is generated inside stainless steel autoclave, under temperature and pressure conditions, in definite duration of time. Surface functionalized graphene has a number of superior advantages for biomedical applications, in particular, manufacturing of attachments for polymer molecules, creating of novel biosurface with graphene, as reinforcement for biopolymer coatings such as ultra-high molecular weight polypropylene (UHMWPE), metallic biomaterials ( $\mathrm{Ti}$ and $\mathrm{Ti}$ alloys) and bioceramics as hydroxyapatite (HA). For example, chemical functionalization of graphene enables this material to be processed by solvent assisted techniques, such as layer-by-layer assembly, spin-coating, and filtration [15]. Surface modification of graphene by SLS surfactant positively improves the attachment of polymer molecules for creating of novel biosurface with graphene [16] [17]. It is also known that surface modification of graphene reduces its toxicity in vitro and in vivo [18]. At the same time, synthesis and surface modification of graphene sheets by SLS surfactant using the one-step solvothermal method and characterizations of as-obtained graphene were described in this work.

\section{Experimental Procedure}

A schematics of solvothermal synthesis method is presented in the Figure 1. Stainless steel autoclave (capacity of $100 \mathrm{ml}$ ) fixed to the metal equipment body, and was connected with temperature controller. Initial substances (total volume $60 \mathrm{ml}$ ), composed of solvent (distilled water-ethanol mixture with 3:1 volume ratio), pure carbon powder $0.3 \mathrm{~g}$ (purity 99.9\%, purchased from Kojundo Kagaku. Co.), sodium lauryl sulfate (SLS) surfactant $\left(\mathrm{C}_{12} \mathrm{H}_{25} \mathrm{NaO}_{4} \mathrm{~S}, 5 \%\right.$ solution, purchased from Kanto Chemical Co. $)$ were placed inside the stainless steel autoclave and covered with lid. Solvothermal reaction temperature was set at $170^{\circ} \mathrm{C}$ with further increase of inner-autoclave pressure to $1.4 \mathrm{MPa}$, and 


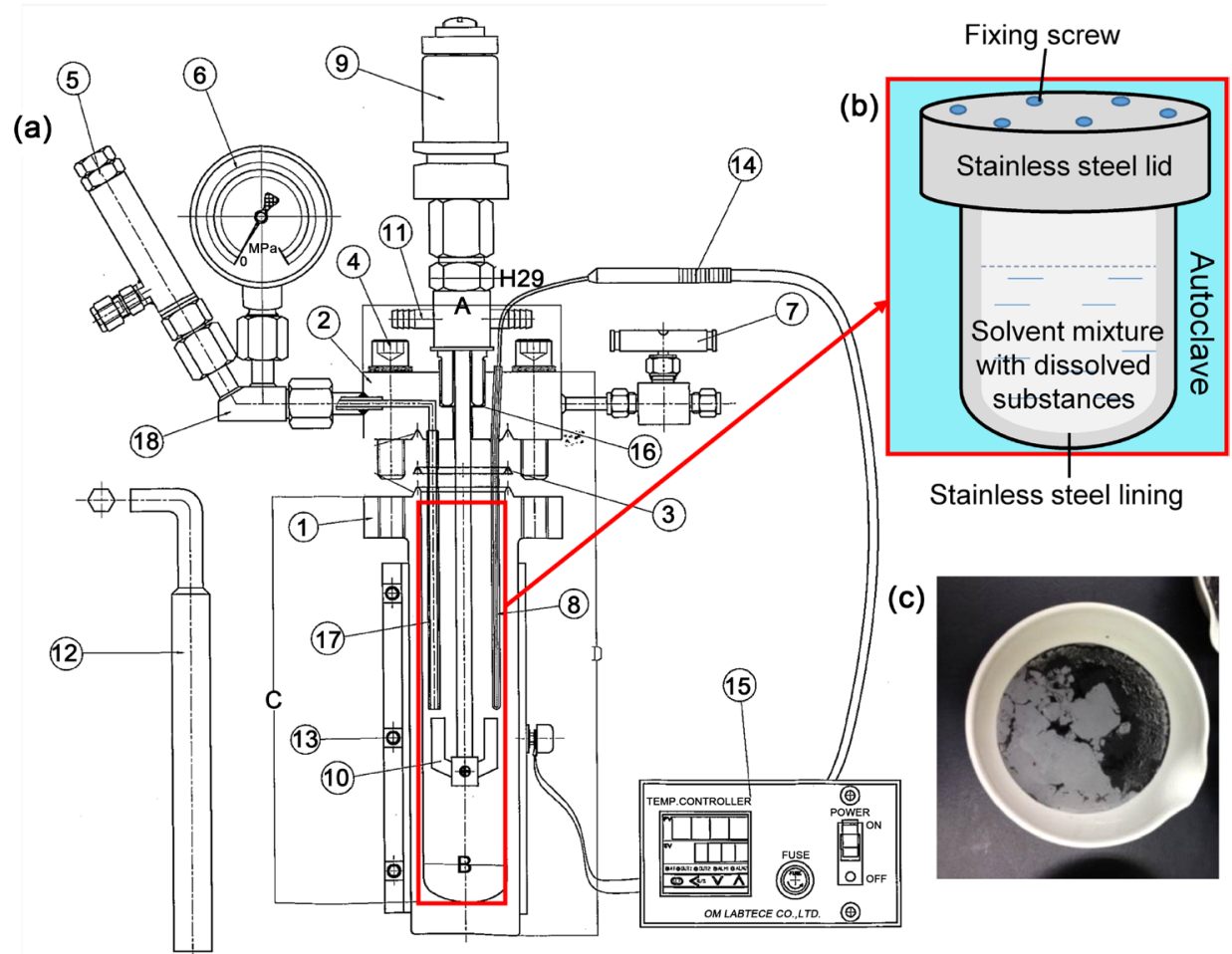

Figure 1. Schematics of experimental setup: (a) Drawing of solvothermal synthesis equipment with labeled compartments: 1-vessel; 2-lid; 3-packing seal; 4-mount seal; 5-safety valve; 6-pressure gauge; 7-valve; 8-thermo well; 9-stirrer; 10-stirring blade; 11-stirrer cooling hose outlet; 12-wrench; 13-heater; 14-thermo sensor; 15-tempertaure controller; 16-rubber seal; 17-specimen pipe; 18-pressure safety branch compartment; (b) Figure of stainless steel autoclave containing initial reaction mixture; (c) Photograph of surface modified graphene sample obtained after solvothermal reaction.

reaction time lasted for 1 hour. Solvothermal synthesis experiment was conducted three times, with SLS surfactant amounts of: $1 \mathrm{ml}, 3 \mathrm{ml}$ and $5 \mathrm{ml}$, for determination of surfactant amount effect on the surface modification of graphene sheets. Graphene sheets with modified surface by SLS surfactant were characterized by high resolution transmission electron microscope (HRTEM) Technai F-20 S-Twin equipped with an Energy dispersive X-ray spectroscopy (EDX) detector for elemental analysis at $200 \mathrm{keV}$. The HRTEM samples were prepared by placing a drop of surface modified by SLS graphene sheets solution (in ethanol) on a holey carbon-coated copper grid. The excess solvent was evaporated and the specimen was dried in a vacuum overnight. X-ray photoelectron analysis was carried out on Thermo Scientific XPS spectrometer. Raman spectrum was collected on HORIBA Jobin Yvon HR800 spectrometer, with He-Ne laser at 516 nm. ATR-FTIR spectra were recorded using the JASCO FT/IR-6300 spectrometer. Atomic force microscopy analyses were conducted on 5500 AFM (N9410S) Keysight Technologies, Inc., with measurement mode: AAC (acoustic ac mode in air).

\section{Results and Discussions}

Multi layered graphene sheets formed after solvothermal reaction were detected by high 
resolution transmission electron microscope (HRTEM) and Raman spectroscopy analyses (Figure 2). HRTEM characterizations, which are proven to be an excellent tool for structure analysis [19], gave us a lot of necessary information regarding the structure, shape location, morphology and sizes of observing materials. Solubilization of carbon powder in ethanol-water mixture at $170^{\circ} \mathrm{C}$ during solvothermal reaction and further graphitization led to formation of graphene sheets. Sonication technique can be applied for synthesis of graphene and separation of graphene multi-layer sheets into single sheets [20] [21], however, our focus was made on solvothermal synthesis and surface modification of graphene, rather than sonication and separation processes. Sonication technique can be applied for synthesis of graphene and separation of graphene multi-
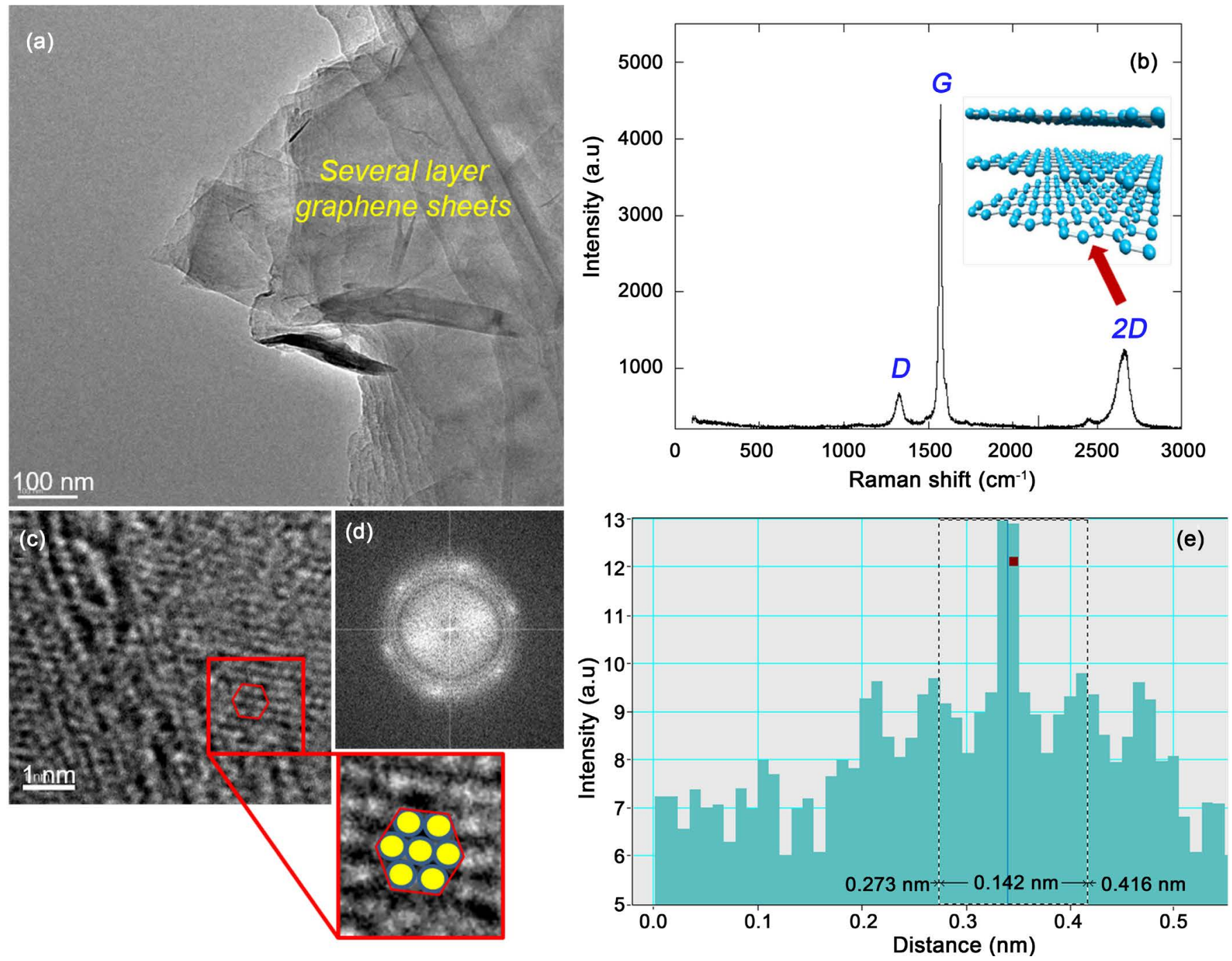

Figure 2. (a) HRTEM photograph of multilayer graphene sheets synthesized by solvothermal reaction method; (b) Raman spectrum collected from graphene sheets synthesized by solvothermal method, by using He-Ne laser beam, inset corresponding to multilayer graphene, inset adapted from [28] by permission of Elsevier; (c) High resolution photograph of graphene at $1 \mathrm{~nm}$ scale, red square shows areas for revealed hexagonal honey-comb lattice structure of graphene, inset is enlarged area shown in red square in (c), corresponding to the inter-atomic distance of $0.142 \mathrm{~nm}$ between C-C covalent bonds; (d) FFT image taken parallel with HRTEM observation; (e) Peak profile showing inter-atomic distance between C-C bonds equal to $0.142 \mathrm{~nm}$. 
layer sheets into single sheets [22] [23], however, our focus was made on solvothermal synthesis and surface modification of graphene, rather than sonication and separation processes. Similar to previously reported works [22]-[24], solvothermally synthesized graphene exhibited analogical structures and dimensions. Inter-atomic distance between C-C bonds in solvothermally synthesized graphene are coincident with mechanically exfoliated graphene, were equal to $0.142 \mathrm{~nm}$ [25] [26]. Comparing to other works, solvothermally synthesized graphene was stable against oxidation, whereas surface modified graphene by various surfactants [27] [28] were undergo reduction and oxidation as well.

Raman spectroscopy was used to study the number of layers and structure of surface modified graphene sample synthesized by solvothermal method. Peaks for $D$ band at $1327.29 \mathrm{~cm}^{-1}, G$ band at $1572.5 \mathrm{~cm}^{-1}$ and second ordered $2 D$ band at $2663.54 \mathrm{~cm}^{-1}$ are detected during Raman spectroscopy analysis. It can be seen that shape and intensity of Raman peaks can be different depending on laser and wavelength type used during analysis [29]. Also, $D$ band in the Raman spectrum can be composed of more than one peak, such as $D_{1}$ and $D_{2}$, which is associated with scattering of electrons by mechanism of double resonance process [30]. Solvothermally synthesized graphene composed of multilayer, which can be explained by the intensity and shape of $2 D$ band peak [31] [32]. The intensity of the $G$ band increases with increased graphene layers, and the shape of $2 D$ band evolves into four peaks of bilayer graphene [33]. The $2 D$ peak in graphene is due to two phonons with opposite momentum in the highest optical branch near the $\mathbf{K}$ ( $A_{1}^{\prime}$ symmetry at $\left.\mathbf{K}\right)[34]$.

Figure 3 shows XPS spectrum collected from surface modified graphene sheets by solvothermal method, inset is C-C line C1s peak detected at $284.7 \mathrm{eV}$ binding energy. Oxidation of graphene was not occurred during solvothermal reaction, which can be seen from the general survey, as there is only carbon atom C1s was appeared, and no oxygen atom peak was detected. Further qualification of obtained data is referred to [35] [36].

ATR-FTIR spectroscopy was applied to determine SLS $\left(\mathrm{C}_{12} \mathrm{H}_{25} \mathrm{NaO}_{4} \mathrm{~S}\right)$ surfactant molecules attached on the surface of graphene sheets. Figure 4 shows ATR-FTIR spec-
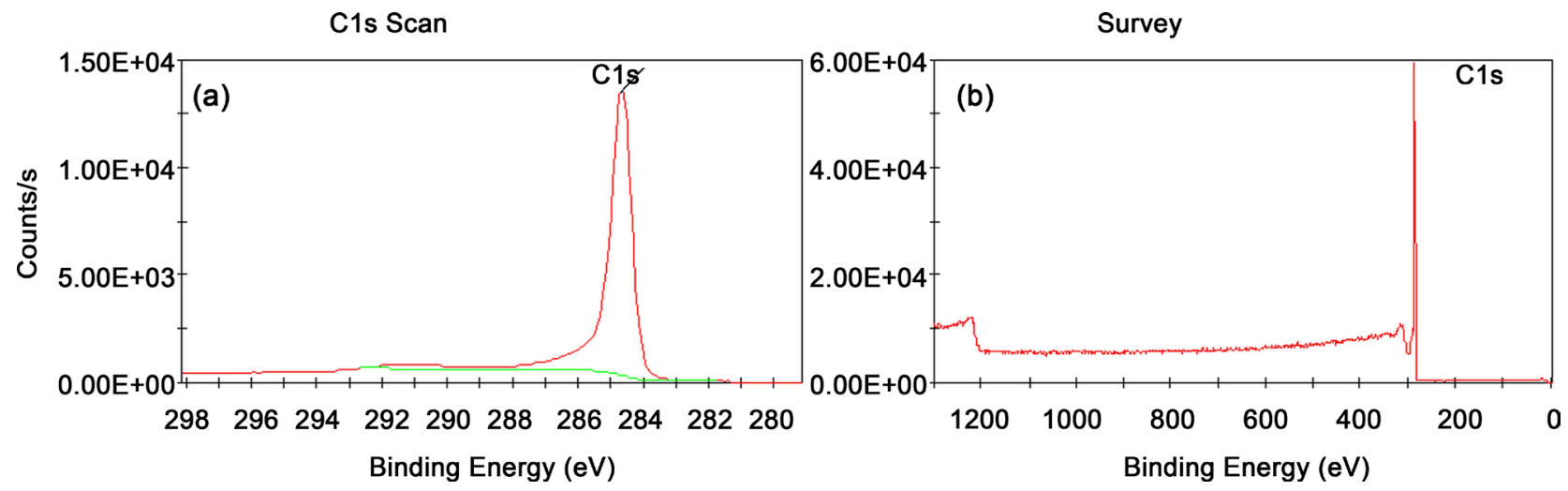

Figure 3. XRS spectra collected from surface modified by SLS surfactant graphene sheets: (a) Scan plot showing single peak for carbon C1s atom at $284.7 \mathrm{eV}$ binding energy; (b) General survey showing peak for C1s carbon atom, and no peak for oxygen. 


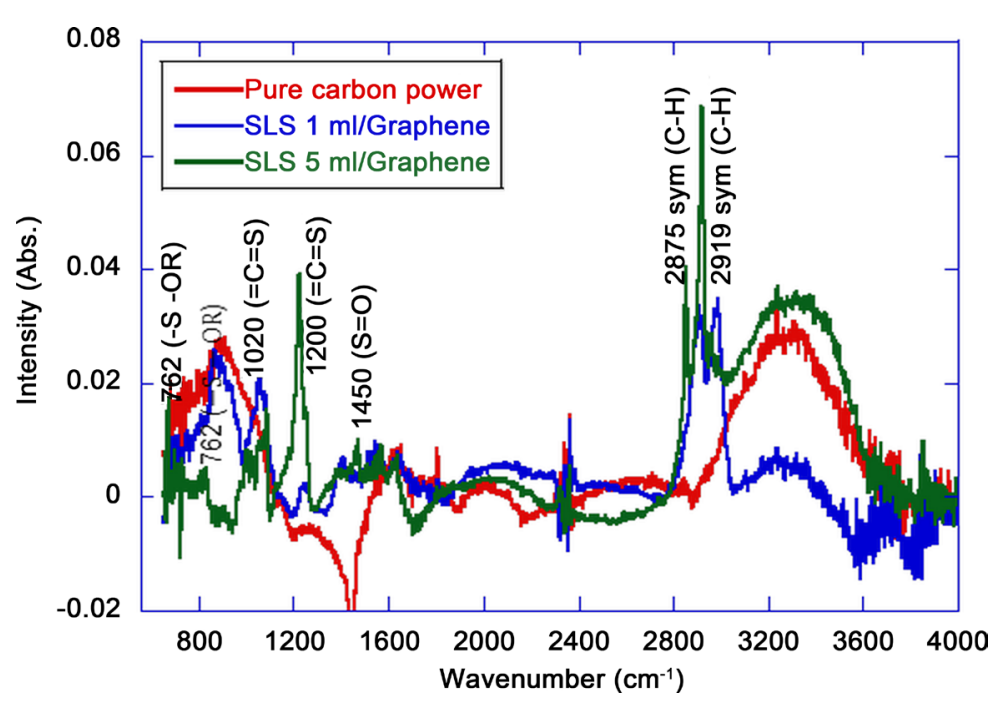

Figure 4. ATR-FTIR spectra of surface modified by SLS surfactant graphene sheets synthesized by solvothermal reaction method. Detected functional groups were released from SLS $\left(\mathrm{C}_{12} \mathrm{H}_{25} \mathrm{NaO}_{4} \mathrm{~S}\right)$ surfactant during solvothermal reaction synthesis.

tra for pure carbon powder, surface modified graphene sheets by $1 \mathrm{ml} \mathrm{SLS}$, and surface modified graphene sheets by $5 \mathrm{ml}$ SLS, respectively. Adding of $5 \mathrm{ml} \mathrm{SLS}$ surfactant to the reaction mixture, provided higher intensity and much more number of peaks belonging to the ether (-S-OR) at $700-900 \mathrm{~cm}^{-1}$, thiocarbonyl $(=\mathrm{C}=\mathrm{S})$ at $1050-1200 \mathrm{~cm}^{-1}$ and sulfone $(=\mathrm{S}=\mathrm{O})$ at $1030-1450 \mathrm{~cm}^{-1}$ functional groups, respectively, in contrast to 1 $\mathrm{ml}$ of SLS surfactant amount.

Also, symmetric $\mathrm{C}-\mathrm{H}$ stretches $\left(\mathrm{CH}_{3}\right)$ at $2875 \mathrm{~cm}^{-1}$, asymmetric $\mathrm{C}-\mathrm{H}$ stretches $\left(\mathrm{CH}_{2}\right)$ at $2919 \mathrm{~cm}^{-1}$ and asymmetric $\mathrm{C}-\mathrm{H}$ stretches $\left(\mathrm{CH}_{3}\right)$ at $2956 \mathrm{~cm}^{-1}$ were detected. Attachment of above functional groups followed by release of them from SLS $\left(\mathrm{C}_{12} \mathrm{H}_{25} \mathrm{NaO}_{4} \mathrm{~S}\right)$ surfactant during solvothermal reaction.

In comparison with other reported methods for surface modification of graphene, solvothermal reaction method have several advantages, such as: use of low temperature energy $\left(1^{\circ} \mathrm{C}-300^{\circ} \mathrm{C}\right)$, short reaction time (1 hour is quite enough), one-step process (synthesis of graphene and its surface modification can be achieved at the same time).

Atomic Force Microscopy is measurement technique, which can provide information not only about physical dimensions, but also let to detect surface features on nanomaterials. Figure 5 presenting AFM images of surface modified by SLS surfactant graphene sheets synthesized by solvothermal synthesis. Figure 5(a) shows solvothermally synthesized graphene sample which was dissolved in ethanol, dropped onto mica substrate and dried prior to observation. As it was discussed earlier [37], SLS surfactant molecules attached onto graphene surface by using of low energy solvothermal reaction method, were observed as protuberant areas on the surface of graphene flakes shown in the Figure 5(a) inside red square, with height profile indication of $4.8 \mathrm{~nm}$. Figure 5(c) shows surface modified graphene sheets by SLS surfactant, when sample was subjected onto HOPG substrate for AFM observation. Line profile in panel (d) represents the average obtained within the yellow line in panel (c), and the virtual nanosheets $\approx 27 \mathrm{~nm}$ 

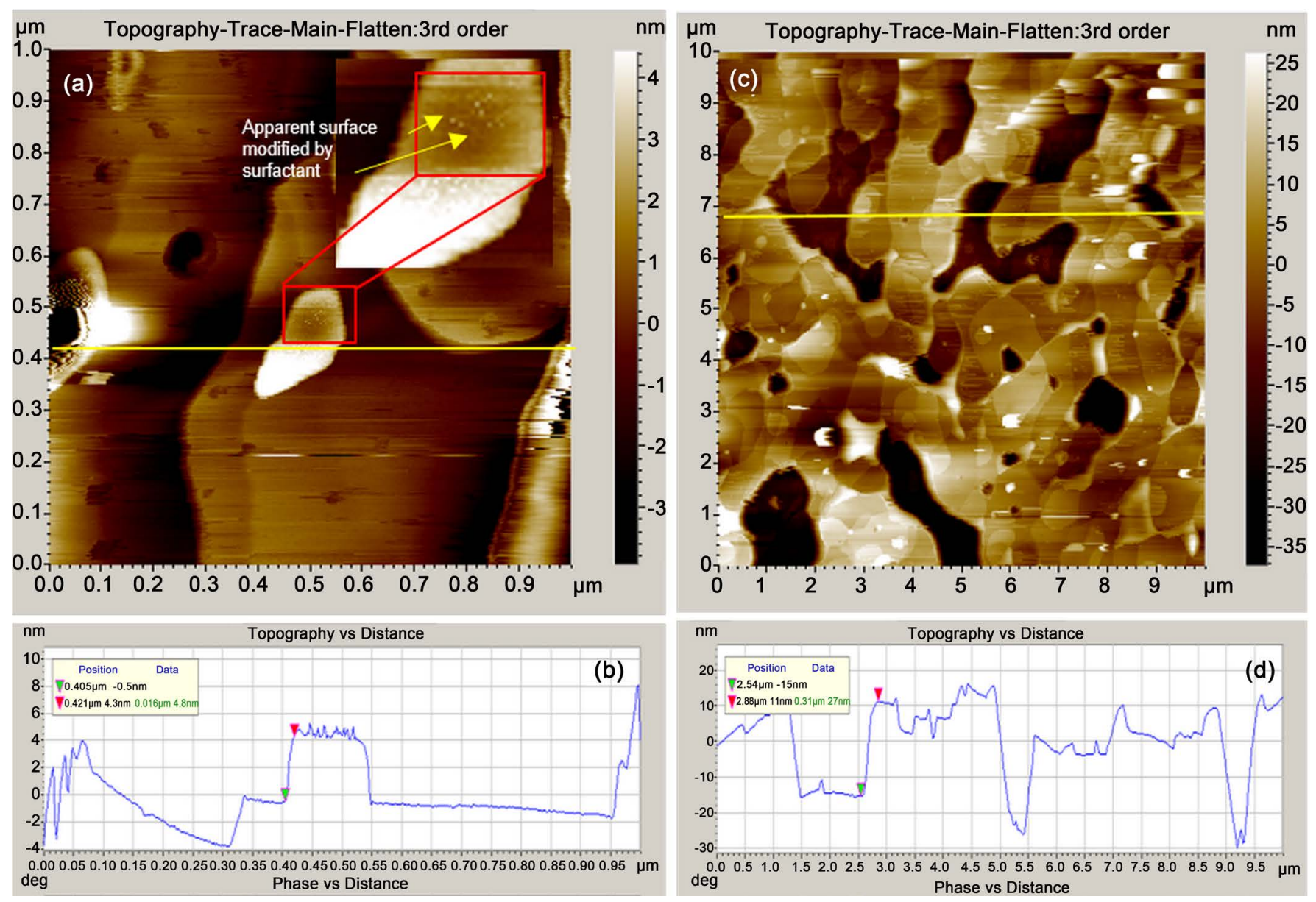

Figure 5. AFM images of surface modified by SLS surfactant graphene sheets synthesized by solvothermal method: (a) AFM image taken by using the mica substrate, inset is enlarged area shown in small red square, arrows indicating surfactant molecules attached to the graphene surface; (b) Height profile projected within the yellow line and showing graphene sheets height equal to $4.8 \mathrm{~nm}$; (c) AFM image of SLS surfactant modified graphene sheets taken using the HOPG as substrate; (d) Line profile obtained within the yellow line in panel (c), and shows graphene nanosheets height attached with surfactant, equal to $27 \mathrm{~nm}$.

high (relative to HOPG substrate).

Table 1 presenting Antibacterial activity of surface modified by SLS surfactant graphene sheets, studied using $3 \mathrm{M}$ Petrifilms for $E$. coli bacterial colonies. It was observed, that antibacterial activity was higher for graphene sheets utilized $5 \mathrm{ml}$ of SLS for surface modification, comparing to samples utilized $3 \mathrm{ml}$ and $1 \mathrm{ml}$ of SLS surfactant. Following results were obtained after average $E$. coli bacteria colonies calculation: for case 136.6 $\mu \mathrm{g} / \mathrm{ml}$ of surface modified by SLS graphene nanosheets, 660 counts for $1 \mathrm{ml}$ of SLS utilization, 570 counts for $3 \mathrm{ml}$ of SLS utilization, and 376 counts for $5 \mathrm{ml}$ of SLS surfactant utilized for surface modification. Antibacterial activity can be initiated by inhibition of metabolic processes [38] in E. coli bacterium colonies.

Summary of graphene family materials discussed [39], indicating slight and nearly no toxic effects of graphene, reduced graphene and oxidized graphene against $E$. coli bacterium colonies.

These obtained results are certainly supporting the biomedical applications of surface 
Table 1. Antibacterial activity of surface modified by SLS surfactant graphene sheets synthesized by solvothermal reaction method.

\begin{tabular}{ccccc}
\hline Sample & $\begin{array}{c}\text { Graphene sheets } \\
\text { modified by 1 ml of SLS }\end{array}$ & $\begin{array}{c}\text { Graphene sheets } \\
\text { modified by 3 ml of SLS }\end{array}$ & $\begin{array}{c}\text { Graphene sheets } \\
\text { modified by 5 ml of SLS }\end{array}$ & Control \\
\hline $\begin{array}{c}\text { Average E. coli } \\
\text { counts }\end{array}$ & 660 & 570 & 376 & 1050 \\
\hline
\end{tabular}

modified by SLS surfactant graphene nanosheets. Graphene elicit toxic effects both in vitro and in vivo, whereas surface modifications can significantly reduce its toxic interactions with living systems [17], which allows biomedical applications of surface modified by SLS graphene sheets, in particular as inner linings and as reinforcement for biopolymer coatings such as ultra-high molecular weight polypropylene (UHMWP), Ti and Ti alloys and hydroxyapatite (HA).

\section{Conclusion}

Synthesis of surface modified graphene sheets by SLS surfactant during solvothermal reaction was highlighted in this work. Atomic state and elemental composition of surface modified graphene were consisted of C-C bonds with inter atomic distance 0.124 $\mathrm{nm}$, and associated with C1s XPS peak, excluding oxidation of synthesized graphene. Multilayer graphene sheets consisting of hexagonal honey-comb lattice were revealed by HRTEM, and structure was determined by Raman spectroscopy. Influence of SLS surfactant amount on surface modification and attached functional groups were determined by attenuated total reflection FTIR spectroscopy. Higher amount of surfactant resulted in much more surface modification areas with higher intensity peaks and quantities of functional groups. Antibacterial activity of surface modified by SLS surfactant graphene sheets is found to be higher in case of increased amount SLS surfactant used during surface modification. Obtained results are highlighting biomedical applications of surface modified by SLS graphene sheets, as biocompatible coating platform between polymer, metallic, ceramic type implants and the living tissue.

\section{Acknowledgements}

This work was funded by start-up research acceleration fund (Funding number: 53511535016) of the Kumamoto University.

\section{References}

[1] Novoselov, K.S., Geim, A.K., Morozov, V., Jiang, D., Zhang, Y., Dubonos, S.V., Grigorieva, V. and Firsov, A.A. (2004) Electric Field Effect in Atomically Thin Carbon Films. Science, 306, 666-669. http://dx.doi.org/10.1126/science.1102896

[2] Geim, A.K. and Kim, P. (2008) Carbon Wonderland. Scientific American, 298, 90-97. http://dx.doi.org/10.1038/scientificamerican0408-90

[3] Geim, A.K. and Novoselov, K.S. (2007) The Rise of Graphene. Nature Materials, 6, 183-191. http://dx.doi.org/10.1038/nmat1849

[4] Saito, R., Fujita, M., Dresselhaus, G. and Dresselhaus, M.S. (1992) Electronic Structure of 
Graphene Tubules Based on C60. Physical Review B, 46, 1804-1811. http://dx.doi.org/10.1103/PhysRevB.46.1804

[5] Gogotsi, Y. (2015) Not Just Graphene: The Wonderful World of Carbon and Related Nanomaterials. MRS Bulletin, 40, 1110-1120. http://dx.doi.org/10.1557/mrs.2015.272

[6] Katsnelson, M.I. (2007) Graphene: Carbon in Two Dimensions. Materials Today, 10, 20-27. http://dx.doi.org/10.1016/S1369-7021(06)71788-6

[7] Katsnelson, M.I. and Novoselov, K.S. (2007) Graphene: New Bridge between Condensed Matter Physics and Quantum Electrodynamics. Solid State Communications, 143, 1-2, 3-13. http://dx.doi.org/10.1016/j.ssc.2007.02.043

[8] Singh, V., Joung, D., Zhai, L., Das, S., Khondaker, S.I. and Seal, S. (2011) Graphene Based Materials: Past, Present and Future. Progress in Materials Science, 56, 1178-1271. http://dx.doi.org/10.1016/j.pmatsci.2011.03.003

[9] Stankovich, S., Dikin, D.A., Piner, R.D., Kohlhaas, K.A., Kleinhammes, A., Jia, Y., et al. (2007) Synthesis of Graphene-Based Nanosheets via Chemical Reduction of Exfoliated Graphite Oxide. Carbon, 45, 1558-1565. http://dx.doi.org/10.1016/j.carbon.2007.02.034

[10] Lee, M.W., Kim, H.Y., Yoon, H., Kim, H. and Suh, J.S. (2016) Fabrication of dispersible Graphene Flakes Using Thermal Plasma Jet and Their Thin Films for Solar Cells. Carbon, 106, 48e55. http://dx.doi.org/10.1016/j.carbon.2016.05.018

[11] Avouris, P. and Dimitrakopoulos, C. (2012) Graphene: Synthesis and Applications. Materials Today, 15, 86-97. http://dx.doi.org/10.1016/S1369-7021(12)70044-5

[12] Zhang, M., Bao, W.X., Liu, X.L., Yu, B.Z., Ren, Z.Y. and Bai, J.T. (2015) Large-Scale Synthesis of Porous Graphene through Nanoscale Carbothermal Reduction Etching. Journal of Materials Science, 50, 7875-7883. http://dx.doi.org/10.1007/s10853-015-9309-1

[13] Johnson, D.W., Dobson, B.P. and Coleman, K.S. (2015) A Manufacturing Perspective on Graphene Dispersion. Current Opinion in Colloid \& Interface Science, 20, 5-6, 367-382. http://dx.doi.org/10.1016/j.cocis.2015.11.004

[14] Al-Latief, D.N., Arnelli, Y. and Astuti, Y. (2015) Synthesis of Sodium Lauryl Sulphate (SLS)-Modified Activated Carbon from Risk Husk for Waste Lead (Pb) Removal. AIP Conference Proceedings, 1699, Article ID: 060017. http://dx.doi.org/10.1063/1.4938371

[15] Kuila, T., Bose, S., Mishra, A.K., Khanra, P., Kim, N.H. and Lee, J.H. (2012) Chemical Functionalization of Graphene and Its Applications. Progress in Materials Science, 57, 1061-1105. http://dx.doi.org/10.1016/j.pmatsci.2012.03.002

[16] Zhou, K., Motamed, T., Thouas, G.A., Bernard, S.S., Li, D., Parkington, H.S., et al. (2016) Graphene Functionalized Scaffolds Reduce the Inflammatory and Supports Endogenous Neuroblast Migration When Implanted in the Adult Brain. PLoS ONE, 11, e0151589. http://dx.doi.org/10.1371/journal.pone.0151589

[17] Guo, X. and Mei, N. (2014) Assessment of the Toxic Potential of Graphene Family Nanomaterials. Journal of Food and Drug Analysis, 22, 105-115. http://dx.doi.org/10.1016/j.jfda.2014.01.009

[18] Shi, S., Chen, F., Ehlerding, E.B. and Cai, W. (2014) Surface Engineering of GrapheneBased Nanomaterials for Biomedical Applications. Bioconjugate Chemistry, 25, 1609-1619. http://dx.doi.org/10.1021/bc500332c

[19] Plachinda, P., Rouvimov, S. and Solanki, R. (2011) Structure Analysis of CVD Graphene Films Based on HRTEM Contrast Simulations. 2011 11th IEEE Conference on Nanotechnology (IEEE-NANO), Portland, 15-18 August 2011, 764-769.

http://dx.doi.org/10.1109/NANO.2011.6144403 
[20] Ciesielski, A. and Samorì, P. (2014) Graphene via Sonication Assisted Liquid-Phase Exfoliation. Chemical Society Reviews, 43, 381-398. http://dx.doi.org/10.1039/C3CS60217F

[21] Sharma, V., Garg, A. and Sood, S.C. (2015) Graphene Synthesis via Exfoliation of Graphite by Ultrasonication. International Journal of Engineering Trends and Technology (IJETT), 26, 38-42. http://dx.doi.org/10.14445/22315381/IJETT-V26P208

[22] Englert, J.M., Dotzer, C., Yang, G., Schmidt, M., Papp, C., Michael, J., et al. (2011) Covalentbulk Functionalization of Graphene. Nature Chemistry, 3, 279-286. http://dx.doi.org/10.1038/nchem.1010

[23] Wang, G., Yang, J., Park, J., Gou, X., Wang, B., Liu, H. and Yao, J. (2008) Facile Synthesis and Characterization of Graphene Nanosheets. Physical Chemistry C, 112, 8192-8195. http://dx.doi.org/10.1021/jp710931h

[24] Dong, P., Yang, Y., Guo, L., Liu, B., Xin, S., Zhang, J., et al. (2012) A Facile One-Step Solvothermal Synthesis of Graphene/Rod-Shaped $\mathrm{TiO}_{2}$ Nanocomposite and Its Improved Photocatalytic Activity. Nanoscale, 4, 4641-4649. http://dx.doi.org/10.1039/c2nr31231j

[25] Park, S.Y., Joon, S.Y.J., Floresca, H.C. and Kim, M.J. (2009) HRTEM Observation of Mechanically Exfoliated Graphene from Natural Graphite and HOPG. ECS Transactions, 19, 81-85. http://dx.doi.org/10.1149/1.3119530

[26] Heyrovska, R. (2016) The Coulombic Nature of the van der Waals Bond Connecting Conducting Graphene Layers in Graphite. Graphene, 5, 35-38.

http://dx.doi.org/10.4236/graphene.2016.52004

[27] Uddin, M.E., Kuila, T., Nayak, G.C., Kim, N.M., Ku, B.C. and Lee, J.H. (2013) Effects of Various Surfactants on the Dispersion Stability and Electrical Conductivity of Surface Modified Graphene. Journal of Alloys and Compounds, 562, 134-142.

http://dx.doi.org/10.1016/j.jallcom.2013.01.127

[28] Kuilla, T., Bhadrab, S., Yao, D., Kim, N.H., Bosed, S. and Lee, J.H. (2010) Recent Advances in Graphene Based Polymer Composites. Progress in Polymer Science, 35, 1350-1375. http://dx.doi.org/10.1016/j.progpolymsci.2010.07.005

[29] Ferrari, A.C., Meyer, J.C., Scardaci, V., Casiraghi, C., Lazzeri, M. and Mauri, F. (2006) Raman Spectrum of Graphene and Graphene Layers. Physical Review Letters, 97, Article ID: 187401. http://dx.doi.org/10.1103/physrevlett.97.187401

[30] Cancado, L.G., Pimenta, M.A., Saito, R., Jorio, A., Ladeira, L.O. and Grueneis, A. (2002) Stokes and Anti-Stokes Double Resonance Raman Scattering in Two-Dimensional Graphite. Physical Review B, 66, Article ID: 035415. http://dx.doi.org/10.1103/physrevb.66.035415

[31] Lloyd-Hughes, J. and Jeon, T.I. (2012) A Review of the Terahertz Conductivity of Bulk and Nano-Materials. Journal of Infrared, Millimeter, and Terahertz Waves, 33, 871-925. http://dx.doi.org/10.1007/s10762-012-9905-y

[32] Beams, R., Cancado, L.G. and Novotny, L. (2015) Raman Characterization of Defects and Do Pants in Graphene. Journal of Physics: Condensed Matter, 27, Article ID: 083002. http://dx.doi.org/10.1088/0953-8984/27/8/083002

[33] Tang, B., Guoxin, H. and Gao, H. (2010) Raman Spectroscopic Characterization of Graphene. Applied Spectroscopy Reviews, 45, 369-407. http://dx.doi.org/10.1080/05704928.2010.483886

[34] Ferrari, A.C. and Robertson, J. (2000) Interpretation of Raman Spectra of Disordered and Amor Phous Carbon. Physical Review B, 61, 14095. http://dx.doi.org/10.1103/PhysRevB.61.14095

[35] Knieke, C., Berger, A., Voigt, M., Taylor, R.N.K., Ro, J. and Peukert, W. (2010) Scalable 
Production of Graphene Sheets by Mechanical Delamination. Carbon, 48, 3196-3204. http://dx.doi.org/10.1016/j.carbon.2010.05.003

[36] Jun, S.C. (2015) Fundamental of Graphene. In: Rashid bin Mohd Yusoff, A., Ed., Graphene-Based Energy Devices, Wiley, Hoboken, 1-48.

http://dx.doi.org/10.1002/9783527690312.ch1

[37] Walch, N.J., Nabok, A., Davis, F. and Higson, S.P.J, (2016) Characterisation of Thin Films of Graphene-Surfactant Composites Produced through a Novel Semi-Automated Method. Beilstein Journal of Nanotechnology, 7, 209-219. http://dx.doi.org/10.3762/bjnano.7.19

[38] Zou, X., Zhang, L., Wang, Z. and Luo, Y. (2016) Mechanisms of the Antimicrobial Activities of Graphene Materials. Journal of the American Chemical Society, 138, 2064-2077. http://dx.doi.org/10.1021/jacs.5b11411

[39] Jastrzębska, A.M., Kurtycz, P. and Olszyna, A.R. (2012) Recent Advances in Graphene Family Materials Toxicity Investigations. Journal of Nanoparticle Research, 14, 1320.

http://dx.doi.org/10.1007/s11051-012-1320-8

Submit or recommend next manuscript to SCIRP and we will provide best service for you:

Accepting pre-submission inquiries through Email, Facebook, LinkedIn, Twitter, etc. A wide selection of journals (inclusive of 9 subjects, more than 200 journals)

Providing 24-hour high-quality service

User-friendly online submission system

Fair and swift peer-review system

Efficient typesetting and proofreading procedure

Display of the result of downloads and visits, as well as the number of cited articles Maximum dissemination of your research work

Submit your manuscript at: http://papersubmission.scirp.org/

Or contact graphene@scirp.org 